\title{
Contribution of Physical Fitness Component to Health Status in Elderly Males and Females over 60 years - Short Report
}

\begin{abstract}
The purpose of this study was to identify the physical fitness (PF) level of a cohort of elderly people that are subjected to physical activity (PA), and to establish a regression model for the evaluation of health status (HS) of elderly people based on their PF. This is a Cross-sectional study. Consists of 114 Participants over 60 years old, that were recruited from a physical activity program. Were measured variables about anthropometric characteristics, jumping tests with jumping platform, dynamic and static balance, risk of falls, lung capacity, HS and quality of life ( $Q o L)$. We used Pearson's

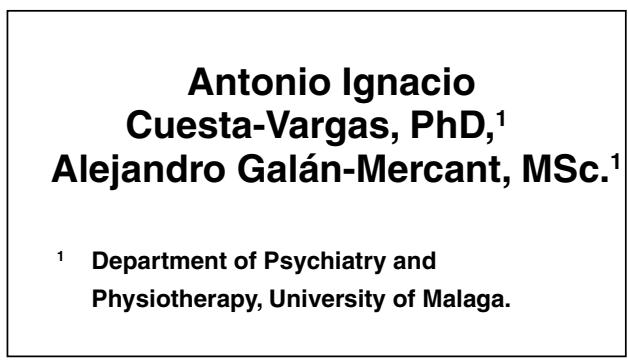
linear correlation with $95 \% \mathrm{Zr}$. We looked for simple and multiple regression models. We used the bayesian information criterion approach and statistical inference to find and calculated a numerical estimate of the best regression model. We used the dependent variable physical function of SF-12. Physical fitness variables selected for the models were weight, height, Countermovement Jump test (flight time), Functional Reach test, lumbosacral flexion mobility, Extended Timed Get Up and Go (ETGUG) (10 meters time score and total time score). The HS and QoL measurement are important for the prevention of injury during physical exercise and should be conducted whenever is possible. The regression models proposed in this study can be used as an initial screening of HS or QoL at fitness facilities and fitness clubs that do not provide HS or QoL questionnaires. However, these models are not an alternative to health care for a detailed determination of $H S$ and is not intended for use as a final evaluation.
\end{abstract}

KEY WORDS: PHYSICAL FITNESS, ELDERLY PEOPLE, HEALTH STATUS, MULTIPLE REGRESSION MODEL.

\section{INTRODUCTION}

The World Health Organization defines Health as a state of complete physical and mental well-being and not merely the absence of disease or infirmity (ACSM 2000). Physical Fitness (PF) is a multifactorial concept that includes characteristics such as body size and shape, weight, body mass index, morphotype, susceptibility to disease and disorders, sensory acuity, functional difficulty, body functioning, recuperative ability, the ability to perform certain

Corresponding Author:

Paseo de Martirícos,

S / N. Physiotherapy Area,

Department of Psychiatry and

Physiotherapy,

University of Malaga,

Malaga. 29009.

E-mail: acuesta@uma.es. tasks, psychological components, and the musculoskeletal system. The musculoskeletal element of health has three sub-components: muscular strength, muscular endurance, and flexibility. If strength, endurance, and flexibility are not maintained, then musculoskeletal fitness may be compromised; this can significantly impact physical health and well-being (ACSM 2000).

There is clear evidence that exercise helps to decrease morbidity and mortality in the elderly and provides many health benefits (Angevaren et al 2008, IMSERSO 2006, Taylor et al 2007). The Centers for Disease Control and Prevention together with the American College of Sport Medicine (ACSM) pu blished a recommendation, where every adult of the United States of America should accumulate over 30 minutes of moderate physical activity (Pate et al 1995). After this study, the ACSM and the American Heart Association presented an update where the ACSM took into consideration the recommendations regarding physical activity in the older American adult population (Haskell et al. 2007). The actual number of facilities with systems for the determination of Health Status (HS), including medical checkups, HS and Quality of Life (QoL) questionnaires, PF tests, is limited due to the lack of operating funds and staff able to handle the equipment used for such purposes (Scheinowitz et al 2008). The results indicated that $\mathrm{HS}$ and level of PF were closely correlated (Sato et al 2005, Sato et al 2006, Sato et al 2007, Sato et al 2009).

Therefore, the aim of this study was to examine in males, females and both together, the relationship between a set of self-report clinical variables, related to the Short Form Health Survey (SF-12) and the EuroQol-5D (EQ-5D), to directly 
measure physical variables related to strength, mobility, dynamic and static balance and spirometry. The second purpose of this study was to identify the PF level in a cohort of elderly people subjected to a PA program

\section{MATERIAL AND METHODS}

Participants. This study presents a cross-sectional study with 114 participants (63 female and 51 male). The mean age of participants was 70.17 years with a standard deviation of 7.3 years and they were recruited for a PA program following the lines of ACSM. It was approved by the Research Ethics Committee of the University of Málaga. After committee approval, we initiated subject recruitment with the corresponding informed written consent. We performed an assessment of individual functional abilities.

Physical Fitness Test. The physical fitness variables selected for the models were weight, height, Countermovement Jump test (flight time), Functional Reach test, lumbosacral flexion mobility, Extended Timed Get Up and Go (ETGUG) (10 meters time score and total time score). The values of the physical fitness assessment are shown in Table 1.

\section{Evaluation of Health Status}

Health Status Questionnaire with the short-form SF-12. The measurement of the HS was determined by questionnaire short-form SF-12, adapted from the long version SF-36. We studied the physical and mental component. The reliability of the SF-12 has demonstrated a high internal consistency with an ICC close to 0.9 (Vigalut et al 2005)

\section{Quality of life related to health with the} EuroQol-5D questionnaire. EuroQol 5 -D is a multidimensional measure of QoL related to health. The reliability and validity of the questionnaire EuroQol 5 -D has been demonstrated in studies of validity and reliability, with ICC of 0.90 (Janssen et al 2008)

Data Analysis. The analysis was guided to the search of differents correlations between clinical variables of QoL and
HS and physical fitness variables of lumbar sagittal mobility, vertical jump, dynamic and static balance and lung function. We looked for simple and multiple regresión models. We proposed diferents multiple regression models to evaluate HS in males, females and both together, we used the bayesian information criterium approach and statistical inference to find and calculated a numerical estimate of the best variables to use in these models. We used SPSS for Windows V 15.0.

\section{RESULTS}

The mean values and range of measure for each PF test item for the group are shown in Table 2.

From the Pearson's linear correlation analyses, significant differences were found between the physical variables and the clinical variables: physical component of SF-12 and Time Up Go Extended total time score (index correlation $=-0.328 p<0.01)$, Euroqol total score and Time Up and Go Exended total time score (index correlation = $-0.309 p<0.01$ ), Euroqol visual analogue scale and Time Up and Go Exended total time score (index correlation $=-0.340 \mathrm{p}<0.01)$, Euroqol visual analogue scale and vertical mark in Countermovement Jump Test (index correlation $=0.299 \mathrm{p}<0.01$ ).

Finally, the most seven relevant physically variables were localized using the Bayesian filtering approach: Weight, Size, Countermovement Jump test (flight time), Functional Reach test, lumbosacral flexion mobility, Extended Timed Get Up and Go (ETGUG) (10 meters time score and total time score). A multiple regression analysis was performed using the physical component of the SF-12 how to depedent variable and the seven relevant variables how to predictor variables. We have found a significant model for the physical component of SF-12 for the males $(p<0.05)$, females $(p<0.05)$ and both together $(\mathrm{p}<0.01)$. The details of models are represented on table 3 .

\section{DISCUSSION}

The main finding from this study was that a set of self-reported clinical variables, related to HS and QoL, could be explained through different directly measured physical variables, related to weight, height, and lumbosacral flexion mobility, as well as the Countermovement Jump Test, the Functional Reach Test, and the Time Up and Go Test.

\section{Predictors of HS and QoL in older adults}

Although the link between functional variables and psychometric variables of physical fitness are often mentioned, few studies have systematically investigated this relationship. To our knowledge, previous studies have identified a detailed conceptual relationship between these components, but in most cases do not provide quantitative data. Regarding increased $\mathrm{HS}$ in the elderly, the PF level must be maintained and increased together with appropriate physical activities and an exercise program (ACSM 2000). There have only been a few studies on the quantitative relationship, although many conceptual relationship studies have been performed. However, in most cases, the correlation level was determined by simple correlation and only a qualitative description of the process.

Our results suggest that the independent variables (related to HS and QoL) could explain $54.7 \%(\mathrm{p}<0.05)$ in males, $46.6 \%(\mathrm{p}<0.05)$ in female, and $44 \%$ $(\mathrm{p}<0.001)$ in both together of the variance in elderly people over 60 years of age. These results show that it is possible to correctly discriminate health status by the level of physical fitness, which is usually considered to be independent of health. This also means that health status can be discriminated with a relatively high degree of accuracy by age and different physical fitness tests results.

As in our study, one recent study (Sato et al 2009) has demonstrated a relationship between anatomy and/or function and health-related quality of life. In this study, we measured PF by 11 variables (height, weight, BMI, \% fat, prehensile strength, flexibility, balance, agility, muscular strength, cardiovascular health and age) and PF was measured using 10 tests and 24 variables (height, weight, BMI, lumbosacral flexion mobility, jumping, static and dynamic balance and spirometry). This recent study (Sato et 
al 2009) estimated HS using different models with different variables, with the PF level varying from $66.5 \%$ to $76.4 \%$. The authors found that increased age increased the probability of becoming ill and also increased the individual differences in PF levels (Sato et al 2009). The presents study estimated the HS in elderly people over 60 years with a model where the PF level intervening in $44 \%$ in the HS for both male and female ( $p<0.01), 54.7 \%$ in the HS for male sample $(\mathrm{p}<0.05)$ and $46.6 \%$ in the HS for female sample $(p<0.05)$.

According our results, we have confirmed the strong influence of different musculoskeletal components to HS and QoL. Similar to the findings of our study on musculoskeletal fitness, one previous study (Kell et al 2001) revealed that if the musculoskeletal components are not maintained, musculoskeletal fitness is then compromised which can significantly impact physical health and wellbeing. Many other studies have identified this relationship between musculoskeletal components and their impact on HS and QoL. Research based on exercise prescription for the elderly (Mazzeo et al 2001) has concluded that cardiovascular and resistance training programs are beneficial to HS and QoL. This finding was similar to those of another study (Kell et al 2001) as well as the results presented in this study, where we confirmed that many health benefits are associated with musculoskeletal fitness. Another study investigating endurance exercise training (Huang et al 2005) quantified the relationship between different physical variables of the musculoskeletal system and QoL and HS.

Regarding the effectiveness, volume and intensity, and the quantification of the dose-response effect of a multimodal program of physical exercise in the elderly, there are several studies of interest, but some limits have been identified. Research on the effectiveness of physical activity interventions (Van Der Bij et al 2002) have provided evidence on the best interventions with high success rates in initiating and maintaining PA. Another study (Baker et al 2007)

Table 1: Assessment of physical fitness.

\begin{tabular}{|c|c|c|c|}
\hline Element & Test (unit) & Method & Reliability/Validity \\
\hline Physique & $\begin{array}{l}\text { Height }(\mathrm{cm}) \\
\text { Weight }(\mathrm{Kg}) \\
\text { BMI; body mass index }\end{array}$ & $\begin{array}{l}\text { The subject barefoot and in underwear } \\
\text { From the vertex to the feet. Subject standing in anatomical } \\
\text { position with the occipital region, back, buttocks and } \\
\text { heels in contact with the height rod } \\
\text { Weight }(\mathrm{kg}) / \text { Height }(\mathrm{m})^{2}\end{array}$ & $\begin{array}{l}\text { Guidelines of the Cinean- } \\
\text { thropometry International } \\
\text { Group (Ross et al 1978) }\end{array}$ \\
\hline $\begin{array}{l}\text { Low back } \\
\text { mobility }\end{array}$ & $\begin{array}{l}\text { Double inclinometry } \\
\text { (degree) }\end{array}$ & $\begin{array}{l}\text { The dual inclinometer IQ DUAL } ® \text { JtechMedical was used } \\
\text { as follows, the primary inclinometer is placed on the space } \\
\text { between T12-L1 vertebral segments and the secondary } \\
\text { inclinometer on S1 segment, then the patient have to } \\
\text { make a maximum trunk flexion with hands together, } \\
\text { arms extended and holding the knees in extension }\end{array}$ & $\begin{array}{l}\text { Pearson correlation of } 0.96 \\
\text { to } 0.99 \text { (Waddell et al 1992) }\end{array}$ \\
\hline Jump & $\begin{array}{l}\text { Countermovement } \\
\text { Jump test: } \\
\text { Flight time (seconds) } \\
\text { Vertical mark }(\mathrm{cm})\end{array}$ & $\begin{array}{l}\text { The GLOBUS ERGOJUMP } \circledast \text { platform-jumping was used } \\
\text { as follows, the subject on the platform, jump from the } \\
\text { standing position with hands placed under the height } \\
\text { of the iliac spines anterosuperiores there is a rapid } \\
\text { extension and flexion of the knee joint with minimal stop } \\
\text { between the concentric and eccentric phases }\end{array}$ & $\begin{array}{l}\text { Interclass correlation index } \\
\text { of } 0.88 \text { for the Countermove- } \\
\text { ment Jump Test (Slinde et a } \\
\text { 2008) }\end{array}$ \\
\hline $\begin{array}{l}\text { Static and } \\
\text { dynamic } \\
\text { balance }\end{array}$ & $\begin{array}{l}\text { Functional Reach test } \\
(\mathrm{cm}) \\
\text { Extended Timed Get } \\
\text { Up and Go (ETGUG) } \\
\text { (seconds) }\end{array}$ & $\begin{array}{l}\text { The difference, in centimetres, between arm's length and } \\
\text { maximal forward reach, using a fixed base of support } \\
\text { The person is asked to stand up from a standard } \\
\text { chair and walk a distance of approximately } 10 \text { meters, } \\
\text { turn around and walk back to the chair and sit down } \\
\text { again }\end{array}$ & $\begin{array}{l}\text { Functional Reach test and the } \\
\text { Time Up and Go Extended } \\
\text { test have been correlated in } \\
\text { a specific study, identifying } \\
\text { a ICC of> } 0.9 \text { (Russel et a } \\
\text { 2008). }\end{array}$ \\
\hline $\begin{array}{l}\text { Lung } \\
\text { Function }\end{array}$ & $\begin{array}{l}\text { FEV1s (milliliters) } \\
\text { FEV6s (milliliters) } \\
\text { FEV1s/FEV6s (milliliters) }\end{array}$ & $\begin{array}{l}\text { The amount of air that you can forcibly blow out in one } \\
\text { second } \\
\text { The volume that is ejected in the first six seconds of a } \\
\text { forced exhalation } \\
\text { Ratio FEV1s / FEV6s }\end{array}$ & $\begin{array}{l}\text { In healthy adults, this should } \\
\text { be approximately } 75-80 \% \\
\text { (Tiffenau et al 1956) }\end{array}$ \\
\hline
\end{tabular}


Table 2: Descriptive characteristics of the sample $(n=114)$.

\begin{tabular}{|c|c|}
\hline Variable (Unit) & Mean $(95 \% \mathrm{Cl})$ \\
\hline Age (years) & 70.17 (62.87 to 77.47$)$ \\
\hline Weight (Kg) & 73.15 (59.44 to 86.86$)$ \\
\hline Size (m) & $1.56(1.48$ to 1.64$)$ \\
\hline Body mass index (Kg/m2) & 29.92 (25.52 to 34.32$)$ \\
\hline Lumbosacral flexion mobility in the sagittal plane (degrees) & 43.06 (6.77 to 122.35$)$ \\
\hline Countermovement Jump Test, flight time (seconds) & 0.21 (0.11 to 0.31$)$ \\
\hline Countermovement Jump Test, vertical mark (seconds) & $0.26(0.16$ to 0.36$)$ \\
\hline The Functional Reach Test (centimetres) & 22.5 (15.44 to 29.56$)$ \\
\hline The Time Up and Go Extended Test (seconds) & 17.63 (12.61 to 22.65$)$ \\
\hline Spirometry FEV1s (millilitres) & $1.25(0.45$ to 2.05$)$ \\
\hline Spirometry FEV6s (millilitres) & $4.09(-25.11$ to 33.29$)$ \\
\hline Spirometry Ratio FEV1s / FEV6s (millilitres) & $4.07(-29.33$ to 37.47$)$ \\
\hline SF-12 (physical component) & $47.44(38.27$ to 56.61$)$ \\
\hline SF-12 (mental component) & 44.99 (34.81 to 55.17$)$ \\
\hline Euroqol total score & 0.79 (0.56 to 1.02$)$ \\
\hline Euroqol visual analogue scale & $72.62(52.31$ to 92.93$)$ \\
\hline
\end{tabular}

Table 3: Multiple regression analysis.

\begin{tabular}{|c|c|c|c|}
\hline Depedent Variable & Predictor Variables & Standardized B & $\mathbf{R 2}$ \\
\hline $\begin{array}{l}\text { Physical function of SF-12 } \\
\text { (male and female together) }\end{array}$ & $\begin{array}{l}\text { Weight } \\
\text { Height } \\
\text { CMJ (flight time) } \\
\text { Functional Reach test } \\
\text { Lumbosacral flexion mobility } \\
\text { TUG (12 metres) } \\
\text { TUG (total score) }\end{array}$ & $\begin{array}{l}-0.117 \\
0.200 \\
0.299 \dagger \\
-0.134 \\
0.165 \\
0.180 \\
-0,358+\dagger\end{array}$ & $0.440^{\star \star}$ \\
\hline $\begin{array}{l}\text { Physical function of SF-12 } \\
\text { (male) }\end{array}$ & $\begin{array}{l}\text { Weight } \\
\text { Height } \\
\text { CMJ (flight time) } \\
\text { Functional Reach test } \\
\text { Lumbosacral flexion mobility }\end{array}$ & $\begin{array}{l}-0.197 \\
0.435 \dagger \\
0.370 \dagger \\
-0.164 \\
-0,055\end{array}$ & $0.547^{*}$ \\
\hline $\begin{array}{l}\text { Physical function of SF-12 } \\
\text { (female) }\end{array}$ & $\begin{array}{l}\text { Weight } \\
\text { Functional Reach test } \\
\text { TUG (total score) }\end{array}$ & $\begin{array}{l}-0.288 \\
-0.141 \\
-0.416 \dagger\end{array}$ & $0.466^{*}$ \\
\hline
\end{tabular}

has presented recommendations on the requirement for the prescription of physical exercise through multimodal treatment programs for the improvement of risk factors for a number of diseases. Finally, one study (Spirduso et al 2001) has also reported that in large sample correlational studies and prospective longitudinal studies, researchers consistently report that measures of physical function in older adults are related to feeling of well-being, and that older adults who are physically active also show higher levels of well-being and physical function. However, the results of a randomized intervention study on aerobic and/or resistive strength training do not support this relationship. Even 
if changes in well-being and physical function were reported, no evidence was found that levels of intensity operated in a dose-response fashion to influence these changes. Therefore, an analysis of the contribution of different PA factors to HS and QoL, as demonstrated in the present study, could help to remove these limitations.

PF level is a multidimensional quantitative component which lies within the HS. In future research, it would be interesting to establish the volume and intensity of multimodal exercise programs in older people through randomized clinical trials with individual dose-response curves. Moreover, the effects of multimodal exercise programs in older people should be examined. It would be interesting to study individual quantitative factors (genetic, biochemical, anatomical, biomechanical and physiological) that show an influence on HS and QoL.

The clinical implication of this study is that, having identified the clinical predictor variables that improve the perception of health status and quality of life, and given that some of these factors are modifiable, there is some potential for interventions to selectively increase the perception of health status and quality of life in healthy older adults. Providing interventions for older adults with high body weight, lower strength in the lower limbs, poor mobility in terms of lumbosacral flexion and poor balance may also increase the perception of health status and quality of life.

\section{CONCLUSSION}

The PF level of the participants was calculated using ten test and twenty four difirent physical variables. The effectiveness of the variables was examined using the bayesian filtering approach and statistical inference. We found a significant relationship between differents clinical and physical variables in the simple and multivaiant correlation examinations.

The HS and QoL measurement are important for the prevention of injury during physical exercise and should be conducted whenever is possible. The regression models proposed in this study can be used as an initial screening of HS or QoL at fitness facilities and fitness clubs that do not provide HS or QoL questionnaires. However, these models are not an alternative to health care for a detailed determination of HS and is not intended for use as a final evaluation.

\section{REFERENCES}

American College of Sports Medicine (ACSM) 2000 General principles of exercise prescription In: A.C.S.M.'S. Guidelines for exercise testing and prescription. 6th edition. Philadelphia Lippincott Williams \& Wilkins.

Angevaren M, Aufdemkampe G, Verhaar HJJ, Aleman A, Vanhees L 2008 Physical activity and enhanced fitness to improve cognitive funtion in older people without known cognitive impairment. Cochrane Database Syst (2) CD005381.

Baker MK, Atlantis E, Fiatarone MA 2007 Multimodal exercise programs for older adults. Age Ageing 36: 375-81.

Centers for the Disease Control and Prevention (CDCP) 2004 Prevalence of no leisure-time physicaly activity - 35 States and the district of Columbia MMWR 53: 83-86.

Haskell WL, Lee IM, Pate RR, Powell KE, Blair SN, Franklin BA, Macera CA, Heath GW, Thompson PD, Bauman A 2007 Physical activity and public health: updated recommendation for adults from the American College of Sports Medicine and the American Heart Association Med Sci Sports Exerc. Aug; 39(8):1423-34.

Huang G, Gibson CA, Tran ZV, Osnesswh 2005 Controlled endurance exercise training and VO2max changesin olders adults: a meta-analysis. Prev Cardiol 8(4): 217-25.

Instituto de Mayores y Servicios Sociales (IMSERSO) 2006 Informe 2006, Las Personas Mayores en España, Datos Estadísticos Estatales y por Comunidades Autónomas. Ministerio de Trabajo y Asuntos Sociales. Secretaría de Estado de Servicios Sociales, Familias y Discapacidad. Instituto de Mayores y Servicios Sociales (IMSERSO),

Janssen MF, Birnie F, Heagsma JA, Bonsel GJ 2008 Comparing the standard EQ-5D three levels system with a five levels version. Value Healt; 11:275-289.

Kell RT, Bell G, Quinney A 2001 Musculoskeletal fitness, health outcomes and quality of life. Sports Med, 31(12): 863-73.

Mazzeo RS and Tanaka H 2001 Exercise prescription for the elderly: current recommendations. Sports Med 31(11): 809-18.

Pate R, Pratt M, Blair S 1995 Physical activity and public health. A recomendation from the Centers for Disease Control and Prevention and the American College of Sports Medicine. JAMA 273(5): 402-7.
Ross W, Hebbelinck M, Faulkner R, 1978 Kinantropometry terminology and landmarks. in Shepard R, and Lavalle H. Physical Fitness Assessment. Charles tomas. Sprinfield.

Russel MA, Hill KD, Blackberry I, Day LM, Dharmage SC 2008 The reliability and predictive accuracy of the falls risk for older people in the community assessment tool. Age Ageing, 27(6): 634-9.

Sato T, Demura S, Murase T, Kobayashi Y 2005 Quantification of relationship between health status and physical fitness in middle-aged and elderly males and females. Journal of Sports Medicine and Physical Fitness 45: 561-569.

Sato T, Demura S, Murase T, Kobayashi Y 2006 Contribution of physical fitness component to health status in middle-aged and elderly males. Journal of PhysiologicalAnthropology 25:311-319.

Sato T, Demura S, Murase T, Kobayashi Y 2007 Contribution of physical fitness component to health status in middle-aged and elderly females. Journal of Physiological Anthropology 26: 569577.

Sato T, Demura S, Murase T, Kobayashi Y 2009 Estimation equation for the evaluation of the health status of middle-aged and elderly individuals based on the results of physical fitness test: a proposal for use as an initial screening test. Human Performance Measurement Vol. 6: 1-9.

Scheinowitz M, Dankner R, Goldbourt U, MaromKlibansky R 2008 Pre-participation screening of individuals engaging in noncompetitive physical activity. Harefuah 147(7):611-7.

Slinde F, Suber C, Suber L, Edwén CE, Svantesson U 2008 Test - retest realibility of three different countermovement jumping test. J Strength Cond Res 22(2): 640-4.

Spirduso WW, Cronin DL 2001 Exercise doseresponse effects on quality of life and independent living in older adults. Med Sci Sports Exerc 33: S598-608.

Taylor NF, Dodd KJ, Shields N, Bruder A 2007. Therapeutic exercise in physiotherapy practise is beneficial: a summary of systematic reviews 2002-2005. Aust J Physiother 53: 7-16.

Tiffenau R, Dunoyer P 1956 Action of cortisone on the pulmonary cholinergic hypersensitivity of the asthmatic patient. Presse Med. 64(31): 719-21.

Van Der Bij AK, Laurant MG, Wensing M 2002 Effectiveness of physical activity interventions for older adults: a review. Am J Prev Med 22(2): 120-33.

Vigalut G, Valderas JM, Ferrer M, Lopez-Garcia E, Garin O, Alonso J 2008 Interpretation of sf36 and sf12 questionnaires in Spain: physical and mental components. Medicina Clínica, 130(19): 726-35.

Waddell G, Somerville D, Henderson I, Newton M 1992 Objective clinical evaluation of physical impairment in chronic low back pain. Spine 17: 617-628. 